\title{
SPONTANEOUS ELIMINATION OF INHALED GRASS INFLORESCENCES THROUGH THE LUNG AND CHEST WALL
}

BY

\author{
C. CHOREMIS, S. THEODOROU, TH. ATHANASIADES, and H. KATERELOS \\ From the Paediatric Clinic of University of Athens, Greece
}

(RECEIVED FOR PUBLICATION DECEMBER 16, 1963)

Grass inflorescences as foreign bodies in the respiratory tract are rare, 45 cases having been recorded to date. Jackson (1960) made a comprehensive study of the subject and reviewed the published material as far back as 1794: he found reports of only 35 cases. In 1955, Woolley reported 3 cases of inhaled grass inflorescences and Godfrey (1957) added 2 new cases. Holinger and Johnston (1954), in a classification of 2,042 cases of various types of foreign bodies in the air and food passages, made no mention of grass inflorescences. According to Jackson (1960), the fate of inflorescences entering the respiratory tract depends upon their botanic characteristics which produce two distinct clinical types. In the first, because of their construction, inflorescences remain in the bronchi until removed bronchoscopically; in the second, to which the majority of cases belong, inflorescences, owing to their ability to travel towards the periphery, penetrate the parenchyma of the lung, the pleural layers, and the intercostal muscles and finally protrude under the skin of the chest wall.

There are a few points that should be emphasized. (1) Grass inflorescences belong to the group of foreign bodies inhaled mainly by young children. (2) Because of their shape, inflorescences do not produce bronchial obstruction and therefore give no acute symptoms. (3) During their stay in the lung (which varies from a few days to many months) it is difficult to detect them with the bronchoscope, while the clinical signs are persistent and rather bizarre, thus creating a difficult diagnostic problem. The following are reports of two cases of inhaled grass inflorescences that were spontaneously eliminated from the thoracic wall.

\section{Case Reports}

Case 1. A 3-year-old girl, was admitted to hospital on May 9, 1959 because of pyrexia. Her parents mentioned that the child probably had swallowed a piece of wood 40 days previously and although she presented no symptoms at the time, she had to be admitted to a hospital six days later, because of diffuse abdominal pains, diarrhoea, and pyrexia. She was treated with chloramphenicol for two weeks, her sym ptoms subsided, and she was discharged home. The following day she again had a high temperature and was, therefore, brought to the paediatric department of Athens University.

Physical Findings. There was dullness over the left side of the chest, diminished air entry, and scant râles particularly throughout the left lower lobe. A radiograph of the chest (Fig. 1) showed density of the left lower lobe and obliteration of the left costophrenic sinus. She was treated with penicillin, streptomycin, and chloramphenicol, but in spite of this the temperature remained high $\left(39^{\circ}-40^{\circ}\right.$ C.). Two days later, she developed nasal catarrh, redness of the conjuctivae and cough and, in the next 3 days, the typical rash of measles.

LABORATORY FINDINGS. White cell count 12,000 per c.mm., neutrophils $68 \%$, lymphocytes $32 \%$. Erythrocyte sedimentation rate $50 \mathrm{~mm}$. in first hour and $90 \mathrm{~mm}$. in second hour. Mantoux 1:10,000 was negative.

Course. Seven days after her admission, i.e. 47 days after the probable inhalation of a foreign body, a hard, immobile, and deeply seated nodule about the size of a large pea, appeared at the level of the seventh rib $2 \mathrm{~cm}$. from the posterior axillary line (Fig. 2). During the next few days the temperature remained high, and enlargement of the axillary lymph nodes was noted. An aspiration of the nodule was negative. The swelling gradually increased in size, became inflamed and eventually a yellow spot appeared at its apex. With a small incision a foreign body was removed with ease. This proved to be a $2 \mathrm{~cm}$. long stem of a wheat grass inflorescence (Fig. 3). The clinical signs subsided rapidly and the chest radiographs showed gradual improvement (Fig. 4). The patient was discharged home free of symptoms. 


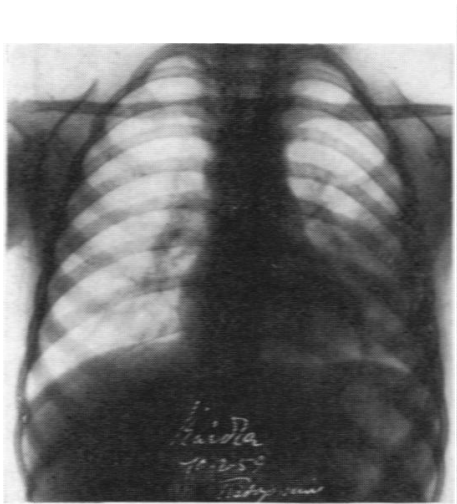

FIG. 1.

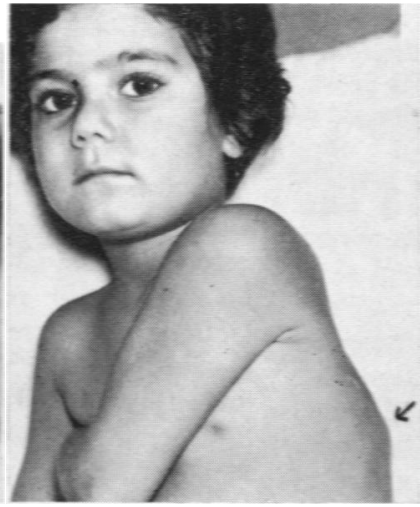

FIG. 2.

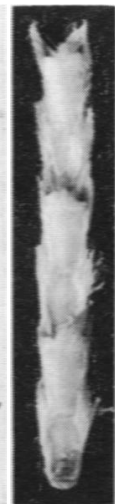

FrG. 3.

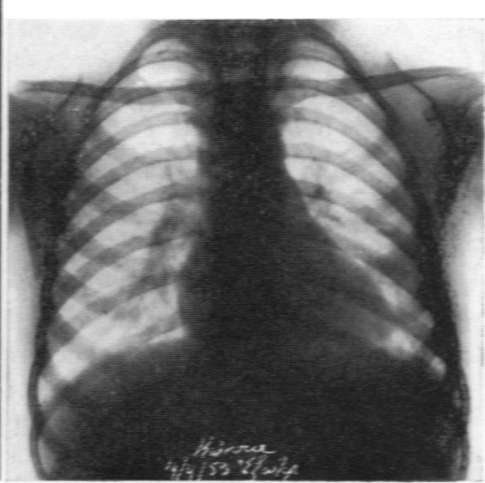

FrG. 4.

FIg, 1-Case 1. Chest radiograph on admission: note shadowing in left lower lobe.

FIG. 2.-Case 1. Photograph of patient showing swelling over posterior aspect of chest.

Fig. 3.- Case 1. Foreign body (wheat stem) removed from an abscess of the chest wall.

Fig. 4.-Case 1. Chest radiograph six weeks after the spontaneous elimination of the foreign body. Almost normal appearance.

Case 2. A boy, $2 \frac{1}{2}$ years of age, was admitted to the paediatric department of the University of Athens. because of dyspnoea and pyrexia. Eight days previously and for no apparent reason he manifested marked dyspnoea, cyanosis, and vomiting. The following day there was a general improvement but he complained of diffuse abdominal pain, slight dyspnoea, and pyrexia $\left(39^{=}\right.$C.). The family doctor prescribed injections of penicillin and streptomycin. A day later the patient developed acute pain in the chest, but again this settled down with no special treatment.

Physical Findings. There was dullness over the right side of the chest; the respiratory sounds were diminished and almost disappeared completely towards the right lower lobe. A small swelling, desply seated and immobile, was found at the level of the seventh rib, near to the posterior axillary line. He was treated with 'Celbenin' (sodium methicillin) and streptomycin. An aspiration of the nodule was negative. Aspiration of the pleural cavity gave a very small amount of purulent fluid, and Staphylococcus aureus grew in culture. The chest radiograph showed shadowing of the lower zone of the right lung (Fig. 5).

LABORATORY Findings. White cells numbered 12,500 per c.mm. on admission and the erythrocyte sedimentation rate was $50 \mathrm{~mm}$. in the first hour and $80 \mathrm{~mm}$. in the second hour. Five days later, the number of the white cells increased to 17,500 and the erythrocyte sedimentation rate to 65 in the first hour and $103 \mathrm{~mm}$. in the second hour.

Course. In the meantime the body temperature settled down to normal, but the swelling at the right side of the chest became larger and inflamed. The swelling was explored through an elliptical incision and a mass

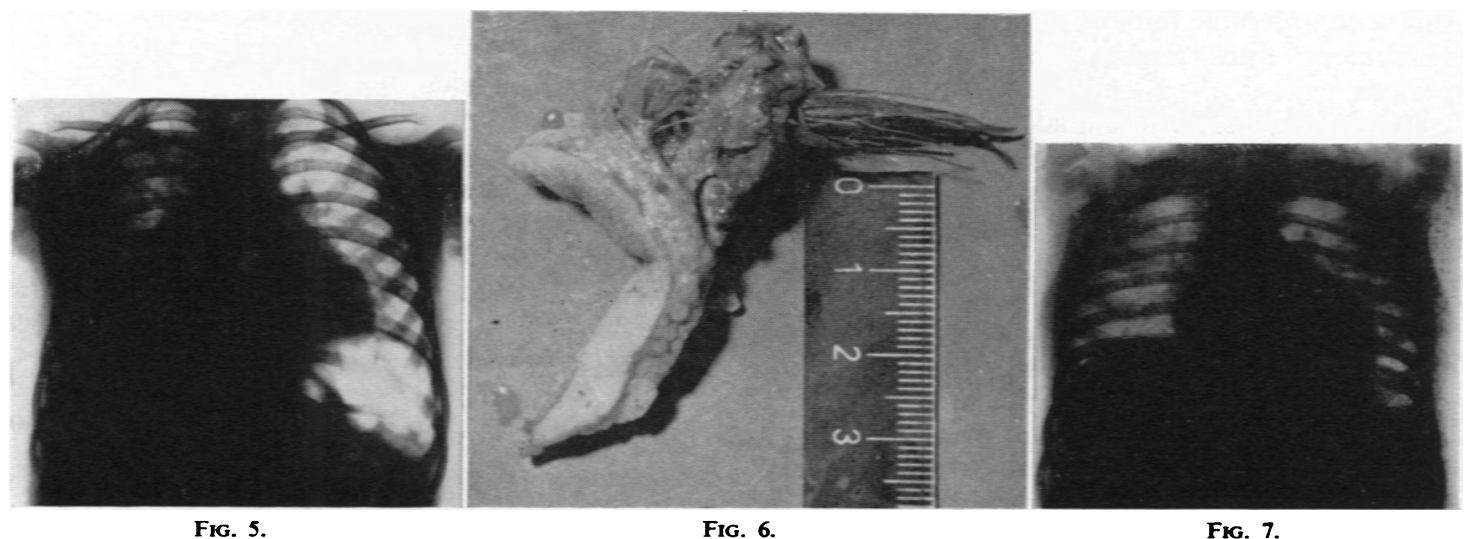

Fig. 5.-Case 2. Chest radiograph taken six days after the inhalation of a grass inflorescence. Note shadowing of lower zone of right lung. FIG. 6. - Case 2. Foreign body (grass inflorescence of Hordeum murinum) removed at operation. The end of the stem was just under the skin while the tail (spikelets) lay deep between the intercostal muscles.

Fig. 7.-Case 2. Chest radiograph taken two weeks after the removal of the foreign body. No abnormalities. 
giving the impression of a dermoid cyst was removed. The apex of this mass was in the intercostal muscles and looked like a tuft of hair. When sectioned, this proved to be a grass inflorescence $5.5 \mathrm{~cm}$. long. It belonged to the species Hordeum murinum (Fig. 6).

The wound healed completely in 15 days and the patient was discharged. A chest radiograph 2 weeks after removal of foreign body showed an almost normal appearance (Fig. 7).

\section{Discassion}

In both our cases the inhaled grass inflorescences migrated through the bronchi, lung, and chest wall and reached the skin. This migration was completed in about two months in the first patient, but took only 10 days in the second. The longer sojourn of the foreign body in the respiratory tract in Case 1 was due to the fact that the wheat stem, deprived of spikelets, was driven slowly towards the periphery, while the arrangement of the spikelets and the elasticity of the stem in Case 2 gave to the inflorescence a particularly fast propulsive ability. Both grasses are extremely common in Greece. In fact children amuse themselves by demonstrating the crawling qualities of inflorescences like barley, wheat, and particularly Hordeum murinum which was found in Case 2, and which grows in almost every field in our country. Children place the spike under their sleeves at the wrists and by rubbing it from above with the other hand, or by just moving the sleeve the grass moves quickly towards the shoulder. The one-way travel of spikes in the respiratory tract is accomplished by the respiratory movements and cough.

There was a history of inhalation of a foreign body in our first case and therefore a diagnosis of pneumonitis due to foreign body was made. No such history existed in the second case, but it is well known that a considerable number of foreign bodies in the respiratory tract remain undiagnosed for long periods.

Referred diffuse abdominal pain seems to be a characteristic clinical manifestation. Our first patient complained of abdominal pains 6 days after the probable inhalation of the foreign body, and the second only 12 hours after the inhalation. Some patients had an unnecessary operation for this reason. In the second of Godfrey's (1957) two patients for instance, an appendicectomy was carried out two days after the inhalation of a foreign body. The appendix was found to be innocent. Because of persistent pulmonary infiltration, a right lower lobectomy was performed about two years later and in the section of the lung a barley grass infiorescence nearly 2 in. long was found. In both our cases the foreign bodies protruded under the skin at the level of the seventh rib at the postero- lateral aspect of the thorax, on the left side in the first case, and on the right side in the second. The right side of the tracheobronchial tree is more frequently affected by foreign bodies for anatomical reasons.

In one case (Godfrey, 1957) the inflorescence, which was similar to the one found in our second case, was eliminated seven weeks after the inhalation in the lumbar region. The radiological findings from the chest are not specific and therefore it is not feasible to make a firm diagnosis on this basis. In any case, foreign bodies in the respiratory tract whose inhalation has been overlooked should not be considered as exceptional rarities. The most valuable help is a detailed medical history. Parents when questioned will usually mention a sudden attack of dyspnoea, cough, or wheezing respiration. These symptoms disappear in the case of inhalation of inflorescences during the next one or two days, as the foreign body does not cause bronchial obstruction but travels continually towards the periphery of the lung. Bronchoscopy should be advised for any suspicious case, but it should be remembered that this procedure becomes fruitless after the foreign body has moved deep into the lung parenchyma.

When a positive history of inhalation of a grass inflorescence exists, and in the presence of clinical and radiological symptoms from the chest attributed to pneumonitis, we think that it is preferable to control infection and wait, instead of advising surgery. There were no serious complications, as far as we know, in any of the cases where spontaneous elimination of the grass inflorescences took place.

\section{Summory}

Two cases of inhaled grass inflorescences that were spontaneously eliminated via the trachea, bronchi, lung, and intercostal muscles out through the skin of the chest wall are described. In the first case a wheat stem, $2 \mathrm{~cm}$. long, was removed from an abscess in the chest wall, and in the second case an inflorescence belonging to the species Hordeum murinum, $5.5 \mathrm{~cm}$. long. The importance of a detailed medical history is emphasized. When a positive history of inhalation of a grass inflorescence exists and when bronchoscopy is negative, operations to the lung should be postponed.

\footnotetext{
Godfrey, R. C. (1957). The behaviour of inhaled grass infliorescences. Lancet, 2, 273.

Holinger, P. H. and Johnston, K. C. (1954). Foreign bodies in the air and food passages. Pediat. Clin. N. Amer., 1, 827.

Jackson, C. (1960). Foreign bodies in the air and food passages. In Otolaryngology, ed. G. U. Coates, H. P. Schenk, and M. Valentine Miller, Vol I, p. 1. W. F. Prior, Hagerstown, Maryland.

Woolky, P. C. (1955). Grass inflorescences as foreign bodies in the respiratory tract. J. Pediat., 46, 704.
}

REPERENCES 